\title{
AS INTERFACES DA FORMAÇÃO DE PROFESSORES E O ADVENTO DA EVASÃO DE PEDAGOGOS(AS): UM ESTUDO DE CASO NO CHÃO UNIVERSITÁRIO
}

\author{
Apresentação: Comunicação Oral \\ Mádson Francisco da Silva ${ }^{1}$; Sineide Maria do Nascimento ${ }^{2}$; Paulo Sérgio Dantas da Silva ${ }^{3}$; \\ Ana Maria Sotero Pereira ${ }^{4}$
}

\section{Resumo}

Este artigo surge à luz da curiosidade do autor, em querer entender melhor os desafios e as perspectivas para a formação de professores e a prática docente no século XXI, e é resultado de uma pesquisa realizada no âmbito acadêmico. Desse modo, este trabalho apontará alguns desafios para as universidades no campo da formação docente, em vista de que muitos estudantes do curso de Pedagogia e outras licenciaturas estão se formando professores, mas, não querem atuar na área, enquanto, outros se formam e querem ser professores induzidos por aquilo que acredita ser sua vocação, mas, conscientes dos desafios de ser professor em tempos modernos em que tal profissão se configura em uma multipluralidade de ações, e se manifestam por saberes individuais e coletivos que se edificam conforme a realidade e o tempo. Nesse horizonte, essa obra trará também alguns motivos pelos quais estudantes de ultimo período em Pedagogia de uma IES não desejam ser professores, e apontar para onde querem ir tais discentes. Como arcabouço teórico, o artigo vai dialogar com Feldmann, Imbernón, Pimenta e outros autores, para sustentar suas análises. No entanto, considera-se que este trabalho objetiva clarear os desafios das IES para a formação de professores, identificando quais são alguns dos emergentes problemas enfrentados na prática pedagógica para que possa-se repensar e buscar maneiras de se caminhar rumo a uma formação teórica mais próxima dos saberes, da ação educativa e de uma escola globalizada em constante mudança.

Palavras-Chave: Formação de professores; prática; profissionalização; evasão.

\section{Introdução}

A educação sempre foi um caminho de realização e de construção humana. E nesse viés, ela é constituída formalmente por escolas, professores, alunos, família e sistemas. Entretanto, o objetivo desse artigo é discutir os desafios das universidades na formação de professores em vista das perspectivas para a prática docente na contemporaneidade, e da evasão de licenciados em docência para outras áreas profissionais. Ressalta-se também nesse trabalho, a dimensão do currículo da formação docente frente à realidade e o contexto educacional nos dias atuais, entrelaçando também os saberes e o poder dos professores em um

\footnotetext{
${ }^{1}$ Pedagogia, Universidade de Pernambuco, mamadson123@hotmail.com

2 Pedagogia, Universidade de Pernambuco, sineidemaria2015@hotmail.com

${ }^{3}$ Geografia, Universidade de Pernambuco, paulo_dantas@outlook.com

${ }^{4}$ Mestre em educação, Universidade de Pernambuco, asotero.upe@hotmail.com
} 
caminho de valorização e profissionalização da carreira docente como caminho de justificar sua práxis. Desse modo, o artigo trás resultados de uma pesquisa qualitativa e mostrará gráficos que representam a intenção de vinte e seis estudantes de ultimo período de pedagogia em serem ou não professores e que curso pretendem realizar ou realizariam fora da docência, mostrando também o curso de pedagogia como primeira ou segunda opção na época de ingresso. Desse modo, esse trabalho trará novas reflexões sobre a formação e a prática docente, indicando novos caminhos a serem descobertos e reutilizados conforme o discernimento de cada um sobre sua realidade educacional.

\section{Fundamentação Teórica}

Naturalmente, quando falamos da formação de professores estamos nos retratando de um grande desafio, em vista, da diversidade ou da multipluralidade que existe dentro de cada sujeito que está em volta do docente e que se faz docente. Sobre essa e outras realidades da formação de educadores, podemos iniciar essa discussão dialogando com Feldmann (2009) que diz que:

\footnotetext{
Formar professores no mundo atual é defrontar-se com a instabilidade e provisoriedade do conhecimento, pois as verdades cientificas perderam seu valor absoluto na compreensão e interpretação de diversos fenômenos. Nesse entendimento, o problema da articulação entre o pensar e o agir, entre a teoria e a prática, configura-se como um dos grandes desafios para a questão da formação de professores. Vivemos em um mundo de incertezas e insegurança. Velhos paradigmas perderam sua força explicativa e agora outros surgem sem, contudo, mostrar ainda sua configuração delineada. (Feldmann. 2009, p. 74)
}

Desse modo, transpassando esse contexto apontado por Feldmann, encontramos na instabilidade e na provisoriedade do conhecimento o currículo da formação de professores, onde este é de suma importância para o curso, pois, é onde se manifesta e se organiza toda a estruturação teórica da possível prática de quem se dispôs a se formar professor. Todavia, diante do questionário aplicado no desenvolver metodológico dessa atividade, encontramos nas respostas dos(as) entrevistado(as) afirmações que caracterizam o currículo como necessário, mas, como inadequado a prática porque a realidade da escola, do processo de ensino-apredizagem e das demais constituições e fazeres da comunidade escolar se afasta das teorias curriculares passadas na vida acadêmica e por vezes nem se aproximam. Nesse horizonte, pode-se dizer que um dos maiores desafios das universidades brasileiras hoje é realmente ter um currículo que atenda a realidade prática da educação e da docência, além de formar docentes que realmente queiram atuar como professores. Talvez, o problema de construir ou manter um currículo de formação mais atualizado, seja um problema para as instituições formadoras dês do inicio dos primeiros cursos de formação docente. Entretanto, 
por mais que o caminho teórico possa se distanciar, ele deve ser redimensionado a práxis, porque não se justifica uma teoria sem prática, uma vez que os fundamentos dela não surgem de meras idéias, mas, de uma observação que resultou em visibilidade de algo ou de alguém. E na compreensão desse caminho de reconstrução e do fazer teoria e prática, podemos nos unir a posição de Pimenta, quando a autora diz que:

\footnotetext{
"A atividade teórica é que possibilita de modo indissociável o conhecimento da realidade e o estabelecimento de finalidades para a sua transformação. Mas para produzir tal transformação, não é suficiente a atividade teórica; é preciso atuar praticamente." (Pimenta. 1997, p. 92)
}

Ou seja, fazendo uma analogia do posicionamento da autora com a discussão desse artigo, revela-se que a experiência docente ou as atividades de pesquisa inseridas na prática e não fora delas, são por natureza o melhor laboratório para se constituir teorias, pelo menos para a realidade ou situação de cada momento, uma vez que a teoria existe para atender uma necessidade prática. Desse modo, um dos desafios da formação de professores é manter o currículo próximo da realidade escolar, e a solução para isso vem ser a pesquisa em educação, os estágios supervisionados, e a adaptação de cadeiras que desenvolvam atividades no viés da ação educativa, com o intuito de romper as barreiras que separam a universidade e a escola. O natural é que esses dois lugares sejam um só campo de conhecimento. Quanto à prática docente ela sempre vai enfrentar desafios, porque o mundo é propicio a essa realidade. Durante toda a história os educadores sempre enfrentaram desafios, e no presente irá passar por outras situações, onde muitas vezes se encontraram com a injustiça, a violência, precariedade e entre outros, mas, a perspectiva docente deve resignificar à história dos próprios professores e alunos, sendo várias estradas de boas possibilidades, apoiadas e estruturadas sobre a inspiração da formação e o prazer de ser professor.

\section{Metodologia}

Para a construção desse artigo, foi-se utilizado o método da pesquisa qualitativa em educação, para se alcançar o maximo de entendimento sobre as indagações que norteiam essa obra. Sendo assim, justifica-se a pesquisa qualitativa como uma investigação que busca compreender as pessoas e as coisas na sua essência. Nesse viés, Oliveira (2012) entende a ‘ pesquisa qualitativa como sendo um processo de reflexão e análise da realidade[...] em seu contexto histórico e/ou segundo sua estruturação." Ou seja, o que Oliveira quer dizer, é que esse tipo de abordagem pressupõe e conduz quem investiga ao intimo do que está sendo 
investigado. Ainda sobre esse tipo de pesquisa, pode-se considerar que ela induz a investigação a compreender e a indagar mais ainda todos os fatores e os fenômenos que circulam e norteiam os sujeitos em suas ações, assim como também, as coisas. Nessa perspectiva qualitativa, foi-se utilizado o estudo de caso, que segundo Fachin(2006) “é caracterizado por ser um estudo intensivo. No método do estudo de caso, leva-se em consideração, principalmente, a compreensão, como um todo, do assunto investigado." $\mathrm{Ou}$ seja, faz-se uma análise real e geral de todo o fenômeno existente e que surge na pesquisa.

Sobre o campo, trata-se de uma IES do estado de Pernambuco e os sujeitos são estudantes do oitavo periodo de licenciatura em pedagogia, sendo dois homens e vinte e quatro mulheres, onde uns já atuam na educação básica e outros(as) não.

Nesse sentido, como instrumento, foi realizado um questionário semiestruturado, com o intuito de buscar nos sujeitos, respostas sobre a sua permanência na prática docente pós formatura ou sua migração para outro campo profissional, assim como também, entender na visão deles os desafios da formação e da prática docente na atualidade onde os mesmos estão inseridos. Sobre o questionario, Oliveira (2012) diz que ele corresponde " à necessidade de coletar dados que facilitem a obtenção de informações para a consecução dos objetivos formulados." Ou seja, facilitar atravéz das respostas dos entrevistados o acesso as informações ou respostas para a investigação. Depois de coletar as informações em questionário, foi realizada a análise de conteúdo, porque ela proporciona o entendimento das coisas e dos fatores, a partir dos registros construídos e escritos encontrados no campo da investigação, que nesse caso é as respostas dos licenciandos no questionário semi-estruturado. Nesse sentido, Caregnato e Mutti (2006), entende análise de conteúdo "como sendo uma técnica de pesquisa que trabalha com a palavra, permitindo de forma prática e objetiva produzir inferências do conteúdo da comunicação de um texto replicáveis ao seu contexto social." Ou seja, a análise de conteúdo é os olhos do investigador nas respostas escritas que retratam a realidade dos sujeitos e do campo empírico que está sendo investigado.

\section{Resultados e Discussão}

As discussões dessa temática surgem a partir das atuais possibilidades de evasão de profissionais da educação para outra área profissional. Os dados a seguir, são baseados nas respostas do questionário realizado no caminho metodológico da pesquisa, sendo essa coleta representada por vinte e seis alunos (as) de ultimo período de pedagogia de uma IES do 
estado de Pernambuco, com uma turma de cinqüenta e quatro discentes. O levantamento ocorreu no período de 16 de julho de 2015 á 30 de agosto do mesmo ano.

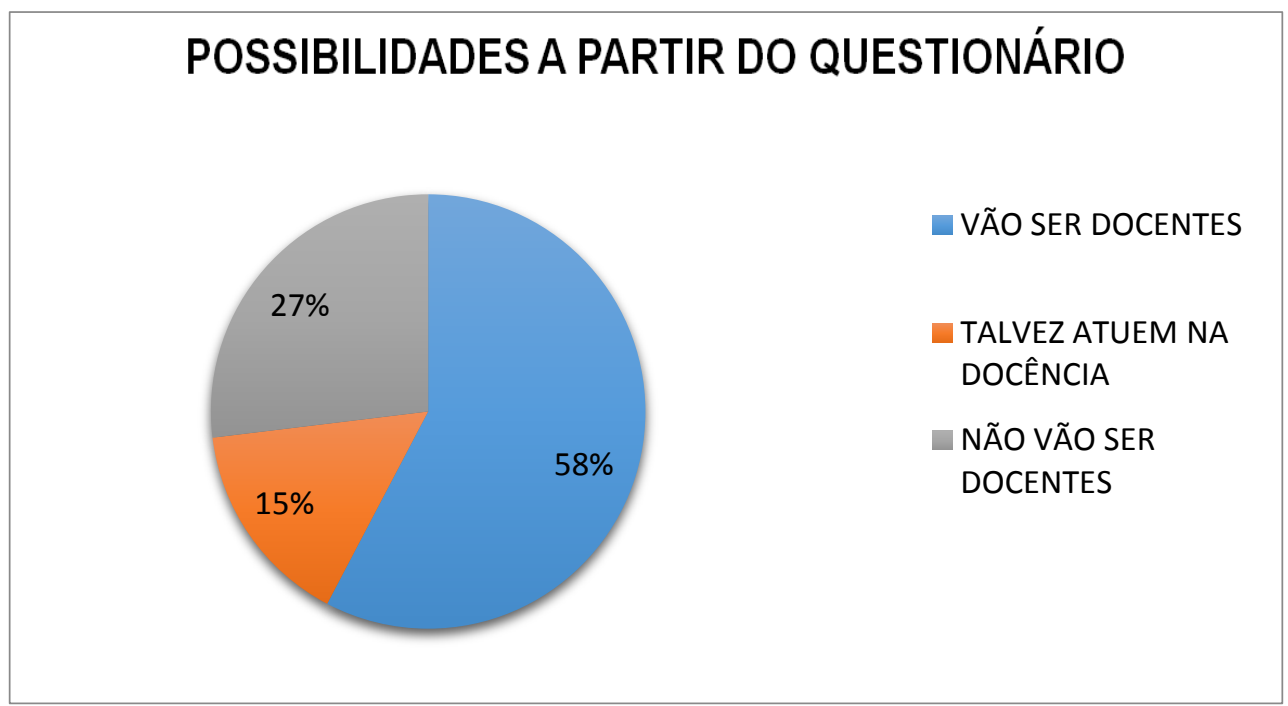

Clareando esse gráfico em números exatos essas porcentagens são: 15 que querem, 4 que talvez atuem e 7 que não vão ser professores de forma alguma.

Como se é possível observar, o levantamento mostra que $27 \%$ dos formandos da docência da instituição pesquisada, estão migrando para outros caminhos ou setores de trabalho, caminhos profissionais estes, que possivelmente os outros $15 \%$ que ainda estão em dúvidas irão caminhar. No questionário aplicado e em convivência com os sujeitos da amostra, percebe-se que essa evasão supracitada ocorre e justifica-se, sobretudo, em vista do descaso com a educação começando pela falta de valorização docente, dos baixos salários, da violência escolar, das lacunas no que diz respeito a recursos financeiros e de fomento pedagógico e formativo, e a ausência da família na escola responsabilizando os professores por uma educação que deveria já vim de casa. E é por esse caminho que se deve repensar a prática docente na sua dimensão pedagógica, para aqueles que querem ser professores, não querendo que o professor assuma o papel da família ou de qualquer outro sujeito, mas, repensar a práxis sobre o contexto real da escola que possui alunos em uma diversidade de fazeres e ser, alunos que pensam, conceituam e estão no mundo muitas vezes de forma incoerente (usando drogas, passando por violência, prostituição e entre outros) e pesam e formam o mundo dentro de suas perspectivas. Desse modo, pode-se considerar necessário repensar inerentemente os saberes e as práticas dos professores contemporâneos e a identidade profissional do professor, para enfrentar os desafios supracitados. Entendendo, que professor é um profissional da educação, 
alguém que está para facilitar e mediar a complexidade do conhecimento cultivando os saberes para um todo. Professor não simplesmente alguém que assume uma vocação e abraça os estudantes como se fosse um médico, psicólogo, pai, amigo, e entre outros que na realidade atual, os professores tem sido obrigado a ser.

Nesses novos tempos do século XXI, que arrasta e mantém muitos pensamentos e práticas erradas sobre o professor e sua profissionalização, precisa-se que os estudantes da docência e os que já atuam na escola, lutem pelos direitos da profissão e da formação, entrelaçando ao que está ligado a sua vivência e ao seu domínio, caminhando de uma forma critica e emancipadora para resignificar a profissionalização docente e seu valor. Sobre isso Imbernón, diz que:

\begin{abstract}
A profissionalização do professor está diretamente ligada ao exercício de sua prática profissional, a qual está condicionada por uma rede de relações de poder. Se a prática é um processo constante de estudo, de reflexão, de discussão, de experimentação, conjunta e dialeticamente com o grupo de professores, se aproximará da tendência emancipadora, crítica, assumindo um determinado grau de poder que repercute no domínio de si mesmo. (IMBERNÓN. 2010, p.36),
\end{abstract}

Ou seja, o caminho a ser trilhado na profissionalização e na valorização docente é segundo o autor, uma estrada que já existe dentro do próprio campo de domínio docente, sendo necessário que os professores relembrem que o poder está na sua prática. Nos dias atuais precisamos de professores que inovem e estejam constantemente investindo na educação. Naturalmente, que a inovação e o investimento surge da boa vontade do professor em querer fazer a diferença na escola, que apesar dos conflitos e das diversas problemáticas é por natureza um lugar de vida, de valorização, de construção de cidadãos e da partilha da cultura, onde a diversidade não deve ser um fator de risco e conflitos, mas fomento ao conhecimento e a mudança positiva de todos. De fato, é necessário que a formação de professores contemporânea esteja atenta a essas dimensões da escola do século XXI.

Por outro lado, pode-se afirmar que $58 \%$ dos entrevistados escolheram o curso como segunda ou ultima opção para não correr o risco de ficar fora da universidade, uma vez que é considerado de mais fácil acesso ao ensino superior, além da vantagem de alguns de morar nas proximidades, ou por ser aparentemente mais fácil e barato de se cursar. Partindo dessa perspectiva, seja em qual for à instituição formadora, é necessário que ocorra para todos uma inerente reflexão sobre o papel dos cursos de formação de professores, "afinal, a universidade abre suas portas para formar professores ou para abrigar refugiados?"

É preciso entender que é evidente que os cursos de licenciaturas não foram criados para ser uma ultima opção, mas, foi criado para gerar formadores que multiplicam saberes, 
constroem profissões e mudam vidas. É necessário que aja por parte da escola, no papel que ela desempenha ou deve desempenhar nos índices de aprovação de vestibulares, uma orientação junto com a família para os vestibulandos para uma opção construtiva na sua vida profissional e pessoal, para que eles não percam tempo e que nem a universidade perca investimentos na formação profissional de professores com quem não quer ser docente, desde muito antes. Na verdade, todos os olhares deveriam ter uma ótica de qualidade para quem quer ser e quem é professor. Uma vez, que qualquer curso que esteja no âmbito da formação de professores, seja pedagogia ou não, merece pleno respeito e valorização, assim como outros cursos que estão na universidade, afinal, estamos falando dos formadores de profissões e sem eles as outras não existiriam. A concepção de que estudantes de licenciatura são pessoas que sabem menos, que tem poucos saberes e habilidades por virem de escolas públicas, que não tem amplo acesso a cultura precisa ser mudada, porque, além de tantas outras coisas que os configuram e os constituem, "são os professores os especialistas em educação" (JARDIM, 2006, p.80). E são esses mesmos professores que formam o Brasil, seja na escola pública ou privada, seja formando futuros docentes ou futuros médicos, porque nesse contexto todos recebem a mesma formação, independentemente no momento o desenvolvimento da aprendizagem de cada um.

O quadro a seguir demonstra a opção dos licenciandos pelo curso de pedagogia no ano de 2011, quando realizaram o vestibular para entrar na IES.

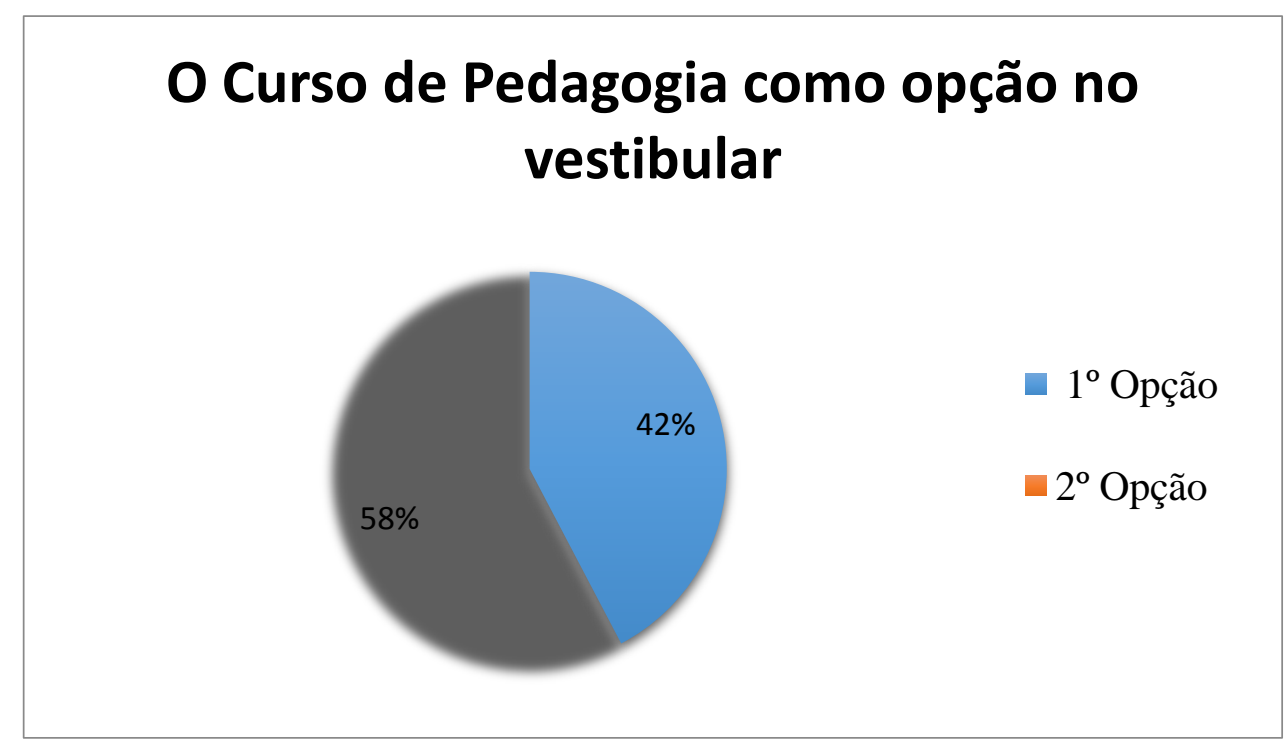

Na sequência, o quadro 1 mostra as profissões almejadas por aqueles que não querem ser professores, enquanto, o quadro 2 mostra as profissões que os candidatos a docência iriam se não fossem atuar. 


\begin{tabular}{|l|l|}
\hline QUADRO 1 & QUADRO 2 \\
& \\
\hline Fisioterapia & Administração de empresas/pessoas \\
Odontologia & Odontologia \\
Secretariado & Assistente Social \\
Empresas & Psicologia \\
Psicologia & Treinamento profissional \\
Gastronomia & Nutrição \\
& Gestão de R. Humanos \\
& Agronomia \\
& Veterinária \\
& Ciências contábeis \\
& Publicidade \\
& \\
& \\
\hline
\end{tabular}

Como pesquisador e até mesmo como universidade, espera-se que diante dos quadros apresentados, os que ficarem para atuar na educação possam fazer a diferença, entendendo a educação como realmente um espaço de mudanças e possibilidades para a sociedade. Enquanto, para o que irão para outras profissões possam cumprir seu papel social na sua profissão.

\section{Conclusões}

Como podemos observar no transcorrer desse artigo, a formação de professores está envolvida por diversos fatores que, sobretudo, envolvem o currículo, a ação educativa e a desistência de licenciados pela educação. Enquanto por outro lado a prática docente é apresentada pelo viés dos desafios contemporâneos da escola, caracterizados pela desvalorização do educador, a indisciplina docente e a falta de recursos para a escola. Entretanto, não se pode esquecer que é pelos cuidados docente que se faz a mudança, é pelo professor que a educação chega nas pessoas e é as pessoas que naturalmente vão sendo transformadas e modificando a realidade. Portanto, no século XXI, o desafio da formação docente pode ser o currículo, mas não pode ser a desistência, o desafio da prática pode ser a falta de recursos, mas não pode ser a falta de inovação e produção do conhecimento, de valores e respeito pela diversidade. Na contemporaneidade os professores podem ser e fazer tudo, menos desistir da educação, para que assim, façam sorrir o rosto de uma sociedade que chora sem muitas vezes perceber as possibilidades de recomeçar. 


\section{Referências}

CAREGNATO,Rita; MUTTI, Regina PESQUISA QUALITATIVA: ANÁLISE DE

DISCURSO VERSUS ANÁLISE DE CONTEÚDO. Texto Contexto Enferm, Florianópolis, 2006 Out-Dez; 15(4): 679-84.

Artigo disponível em: http://www.scielo.br/pdf/tce/v15n4/v15n4a17

Acesso em: 28/05/2015

FACHIN, ODÍLIA. Fundamentos de Metodologia / Odília Fachin, 5ed. [ver.]- São Paulo: Saraiva, 2006. ISBN 978-85-02-05532-2.

FELDMANN, Marina Graziela. Formação de Professores e Escola na Contemporaneidade. Editora Senac São Paulo, 2009.

FREIRE, Paulo. Pedagogia da autonomia: saberes necessários à prática educativa. 9. ed. São Paulo: Paz e Terra, 1996. 165 p.

IMBERNÓN, Francisco. Formação docente e profissional: formar-se para mudança e incerteza / Francisco Imbernón ; [tradução Silvana Cobucci Leite]. - 8.ed.- Cortez, 2010. (coleção questões de nossa época ; v. 14)

JARDIM, A. P. Relação entre Família e Escola: Proposta de Ação no Processo Ensino Aprendizagem. Presidente Prudente: Unoeste, 2006.

OLIVEIRA, Maria Marly de. Como fazer pesquisa qualitativa / Maria Marly de Oliveira. 4. Ed. - Petrópolis, RJ :Vozes, 2012.

PIMENTA, Selma Garrido. O estágio na formação de professores: unidade teoria e prática? $3^{\text {a }}$ Ed. São Paulo, 1997. 